\title{
Green electricity subscription model
}

\author{
ZHENG Xin ${ }^{1,2, a}$, LU Han ${ }^{3, b}$, WU Nannan ${ }^{3, c}$, JIAO Kuo,d \\ ${ }^{1}$ NARI Group Corporation (State Grid Electric Power Research Institute), Nanjing \\ ${ }^{2}$ NARI Electrical Equipment and Engineering Energy Efficiency Evaluation Center, Wuhan \\ ${ }^{3}$ Key laboratory of Regional Energy System Optimization(North China Electric Power University), \\ Ministry of Education, Beijing

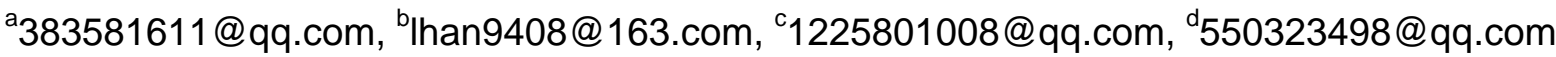

Keywords: green electricity, renewable resources, subscription models, development proposal Abstract. By analyzing the characteristics of renewable resources in China and low carbon power generation situation, the article put forward the concept of green electricity subscription. And according to power system developing model, market situation in our country, green electricity subscription models for the characteristics of China's energy are put forward, which promote the efficient use of green electricity. Moreover, it also provides suggestions for the promotion and implementation of green electricity.

\section{Introduction}

Renewable energy plays a significant role in promoting low carbon development of power system. therefore ,Promoting the use of renewable energy generation can effectively reduce carbon dioxide emissions, which can promote the development of green electricity subscription. the current obstacles of green electricity subscription mainly are the service, the green electricity prices. Therefore, In order to promote the efficient use of green electricity, the article will introduce the new mode of green electricity subscription and promote different green electricity subscription model according to different situations.

\section{Overview of Green Electricity Subscription}

The green power usually refers to hydropower, solar energy, tidal energy, biomass and other renewable energies, there are almost no environmental pollutants. The main purpose of green electricity subscription is to promote the application of renewable energy power generation, reduce fossil fuel power generation, and promote the development of resource-saving society

(1) Foreign Development Situation

Green electricity subscription initially developed in foreign countries. Due to the geographical advantage of Holland, the wind and other renewable energy are rich, as an example, Holland open the study of green electricity mechanism. As shown in Figure 1, at first, it voluntary principle, users have choice of green power purchase according to their own needs. Then they drew into renewable energy the quota system, and combined the two methods. Which greatly promoted the development of foreign green electricity subscription and the promotion of renewable energy. Then they gradually introduced the green certificate concept, and promoted the application of green certificate trading mechanism. The United States and Germany also had certain progress in green electricity subscription $^{[1]}$. Since 1970, the United States had gradually developed green power project in electric power company. In order to promote green electricity, they also set up a series of policies and incentives. With the rapid development of renewable energy, Germany has improving green power pricing system and incentive policies. 


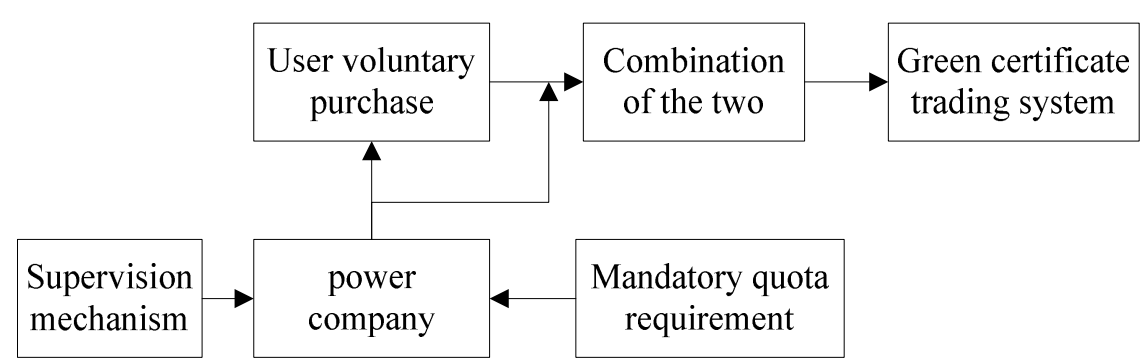

Fig. 1 Development of green electricity subscription mechanism

(2) Domestic Development Status

Different from the developed countries abroad, the research and development of Green Electricity subscription in China is too late. In 2005, Shanghai started the development of green electricity subscription mechanism, but the rate of progress was very slow ${ }^{[2]}$. Over this years, we have learned, the hinder of green electricity subscription is high cost and high price. users have no consciousness purchasing mainly due to the following points:

First of all, Resource development capacity is weak in green electricity subscription, Resource development ability refers to China's renewable energy development and promotion ability is not strong, China's natural renewable energy has non-uniform distribution, which is not benefit to the efficient development of resources.

Secondly, the competition mechanism is defective. Currently the green electricity price is higher than other energy prices on the market. Besides, China's green system is only just beginning, the electricity market mechanism is not perfect, it is very difficult to promote. Therefore, many businesses flinch in the face of this challenge.

In addition, the sales of green electricity is not rich. Because green power market is still in the developing stage, market mode is also gradually worked in marketing programs ${ }^{[3]}$. In addition, It is short of the diversity and adaptability. Therefore, initiative green electricity users is still small.

\section{New mode of green electricity subscription in China}

Summing up the advanced experience of foreign green power research and the main factors hindering the development of green power in China. Combined with China's own energy structure, renewable energy characteristics, the development of power system model, the market situation. In order to develop the green electricity subscription model that suitable for China's energy characteristics.

Through the popularization of energy storage equipment, the development of renewable energy and the amount of Internet access will gradually increase. In addition, our citizens' awareness and acceptance of green electricity is very high, which is conducive to the promotion of green electricity subscription.

(1) green electricity subscription model based on power supply type and carbon emissions

The classification of carbon emissions can expand the scope of green electricity certification. Through the establishment of the relevant grading standards, the power generation enterprises are classified. Among them, wind power, photovoltaic power generation can be divided into excellent green electricity, and part of the electricity consumption in the traditional thermal power generation that implement benchmark price can be divided into qualified green electricity, the user can purchase the corresponding level of green power according to their ability.

(2) a new model of green electricity subscription based on different time periods

It can be divided into several periods according to the variation of the daily load of the power grid. Different electricity prices for different power consumption periods ${ }^{[4]}$. Set a higher price of green electricity at the peak, on the contrary, set a low green electricity price in the electricity trough to form a certain price difference.

(3) a new model of green electricity with green label trading

Green power generation companies can get a green label issued by the government when supply each of the $15 \mathrm{MW}$ green power to the grid, the green label can be used for market transactions, and 
only available in the year. The government stipulates that each generation of power companies must complete a certain quota of green electricity production every year, the enterprise that fail to do so will be fined or even won't be allowed to continue to generate electricity.

(4) a new model of green electricity with green power marketing services

In the green electricity sales, quality service can attract more users to use green electricity. In this mode, Power Grid Corp can set up a green electricity bill, the realization of green electricity subscription information disclosure. Green electricity bill allows users to understand their own green electricity consumption ${ }^{[5]}$. In addition, Power Grid Corp can develop green electricity APP on the phone, users can understand their own green electricity usage and green electricity price in real time through the APP. Besides, through the APP to achieve the purchase of green power and other operations.

\section{Green electricity certification development proposal}

(1) Increase the national allowance for green electricity production

Relative to the thermal power generation, renewable energy power generation is relatively late start. Thermal power generation has remarkable economical benefit. The state also increased the thermal power plant dust, desulfurization and other energy-saving equipment huge subsidies. Compared to thermal power, renewable energy power generation of state subsidies is relatively small, not enough to attract the major power generation enterprises of all ages. Therefore, increase state subsidies for the green power production in the controllable range.

(2) Improve the green power pricing system

The first need to do is to reject the power grid monopoly and promote the green market operation; open and transparent transmission prices; promoting the horizontal development of electricity sales enterprises and enhancing market competitiveness. To promote the market-oriented operation at the same time, government should standardize the competition mechanism, the establishment of the corresponding management requirements, to promote its fair and healthy development; green price customization, the implementation of regional resources due to different prices and set a variety of coexistence model. According to their resources to develop the benchmark price of electricity, and different provinces have some differences.

(3) Add green value-added services

With the gradual development of electricity sales enterprises, through the addition of green value-added services to improve the market competitiveness of the power sales enterprises, while meeting the various needs of users, but also to promote energy-saving emission reduction work. Green value-added services can be carried out by the electricity sales enterprises and energy-saving services companies jointly, can also be provided by the independent power sales enterprises ${ }^{[6]}$. Add green service links, such as intelligent monitoring platform, interactive platform, home intelligent terminal, for green users to provide better service, and thus promote green electricity sales.

(4) Continue to strengthen publicity and promote the popularity of small energy storage equipment

First, the government should strengthen the green power knowledge, green power purchase channels, green power incentives and other related content publicity, and vigorously promote green electricity subscription. The government can advertise the green subscription information through the multimedia platform (advertising, WeChat public platform, mobile phone text messages, open class). Second, the government should promote the popularity of small energy storage equipment, home users and small and medium enterprises can install a reasonable capacity of energy storage equipment, self-produced consumption, which can improve the use of green electricity, environmental protection and energy conservation, reduce electricity costs.

\section{Conclusions}

Starting from the new mode of green electricity subscription, combined with the development of green electricity subscription profile as well as China's own energy structure, renewable energy 
characteristics, power system development model and market situation. Analysis four new modes of green electricity subscription in china, and put forward four suggestions for the future development of green electricity certification. Respectively are: Increase the national allowance for green electricity production, improve the green power pricing system, add green value-added services, as well as continue to strengthen publicity and promote the popularity of small energy storage equipment. In order to promote the efficient use of green power.

\section{Acknowledgements}

This work was financially supported by the National Science and Technology Project of Power Grid Corp (Research on Key Technologies of Carbon Asset Management in power grid enterprises).

\section{References}

[1] Oerlemans L A G, Chan K Y, Volschenk J. Willingness to pay for green electricity: A review of the contingent valuation literature and its sources of error[J]. Renewable \& Sustainable Energy Reviews, 2016, 66:875-885.

[2] Zhang C, Zhou K, Yang S, et al. On electricity consumption and economic growth in China[J]. Renewable \& Sustainable Energy Reviews, 2017, 76:353-368.

[3] Furuoka F. Renewable electricity consumption and economic development: New findings from the Baltic countries[J]. Renewable \& Sustainable Energy Reviews, 2016.

[4] Mulder M, Zomer S P E. Contribution of green labels in electricity retail markets to fostering renewable energy[J]. Energy Policy, 2016, 99:100-109.

[5] Rahbauer S, Menapace L, Menrad K, et al. Adoption of green electricity by German small and medium-sized enterprises (SMEs) - a qualitative analysis[J]. Journal of Cleaner Production, 2016, 129:102-112.

[6] Ayşegül Abuşoğlu, Emrah Özahi, A. İhsan Kutlar, et al. Exergy analyses of green hydrogen production methods from biogas-based electricity and sewage sludge[J]. International Journal of Hydrogen Energy, 2017.

[7] Lee D, Kim M, Lee J. Adoption of green electricity policies: Investigating the role of environmental attitudes via big data-driven search-queries[J]. Energy Policy, 2016, 90:187-201.

[8] Wang F, Zhang B. Distributional incidence of green electricity price subsidies in China[J]. Energy Policy, 2016, 88:27-38.

[9] Chan K Y, Oerlemans L A G, Volschenk J, et al. On the construct validity of measures of willingness to pay for green electricity: Evidence from a South African case[J]. Applied Energy, 2015, 160:321-328.

[10] Julieta Schallenberg-Rodriguez. Renewable electricity support systems: Are feed-in systems taking the lead?[J]. Renewable and Sustainable Energy Reviews, 2017, 76:1422-1439.

[11] Sun Y. The optimal percentage requirement and welfare comparisons in a two-country electricity market with a common tradable green certificate system[J]. Economic Modelling, 2016, 55:322-327.

[12] Bigerna S, Polinori P. Italian households' willingness to pay for green electricity[J]. Renewable \& Sustainable Energy Reviews, 2014, 34(6):110-121.

[13] Arega T, Tadesse T. Household willingness to pay for green electricity in urban and peri-urban Tigray, northern Ethiopia: Determinants and welfare effects[J]. Energy Policy, 2017, 100:292-300. 